\title{
EDITORIAL
}

\section{COMBINING THE BEST OF BOTH WORLDS}

Panacea erupted by COVID-19 outbreak has transformed our personal and political perspectives, on priorities and mode of lives. On March 11, 2020, WHO declared it as a pandemic ${ }^{1}$ followed by a nation wide, smart lock-down. Implementation of social distancing remodeled our sociocultural norms.

To our academic interest, medical education in our country took a giant leap from a traditional face-to-face instruction to online learning. Regardless of how sudden, massive, and unplanned transition it might be, this changed the mode of curricular delivery and groomed our faculty to meet Millennials' expectations ${ }^{2}$. The digital recluse faculty gird their loins, learnt basics of computer and became digital refugees. With hardwork and perseverance, they successfully adapted themselves as digital immigrants to teach a digital native generation!

Adopting online learning is a prolonged process as it requires motivated participants, intense faculty training (on e-learning tools and e-assessments), quality assurance processes and new policies $^{3}$. Due to unexpected circumstances in COVID-19, the learning management system was introduced, abruptly, within days to limit the academic loss which caused apprehension amongst stakeholders. This challenging roller coaster ride experienced by medical teachers was frustrating due to various existing barriers such as technophobia, poor internet connection, traffic overload in online platforms, limited data storage capacity allowed per user in Google classroom etc. Nevertheless, a major challenge was to keep our learners engaged probably because our teaching philosophy was still behaviorism, in sheer contast to Millennial learners preferance of constructivism ${ }^{4}$.

Contrarily, our students readily accepted online education. Nevertheless, they had fewer reservations like feeling of insecurity from computer illiterate faculty, inadequate studentteacher and student-student communication, digital divide, lack of time management and motivation 5,6 . For these digital natives and digital explorers, watching poor quality, pre-recorded lectures was quiet frustrating.

Despite all adversities, e-learning proved beneficial to students in terms of flexible timings, freedom of maintaining own learning pace, reduced time and cost of travel by staying at home, and improved self-efficacy ${ }^{7}$. In addition, it gave us insight to devise novel strategies of learning and assessment e.g., by creating virtual communities of practice like e-discussion forums, shifting our paradigm to guided learning by working on zone of proximal development of our learners and engaging them in tasks that heighten their interest $^{8}$. Asking challenging questions to students, probing for elaboration, providing timely response and a fruitful discourse in live sessions accompanied by formative assessments are some of the ways to enhance their learning and keep them motivated ${ }^{2}$. Moreover, institutional policies on e-assessments tools, graded online activities such as timed quizzes, group presentations, assignments and maintaining portfolios need careful deliberation.

It is evident that students must be on board in new curricular devising process to make it successful. Future of medical studies lies in curricular transformation to hybrid one combining "the best of both worlds" 9 , though it cannot be achieved without faculty training and institutional support ${ }^{3}$.

\section{REFERENCES}

1. Organization WHO. WHO Director-General's opening remarks at the media briefing on COVID-19, 11 March 2020.

2. Hisham D, Mustafa CS.Bakar HA. Moving forward with blended learning as a pedagogical alternative to traditional classroom learning. Malays Online J Educ Technol 2006; 1(3): 11-18.

3. Arsham $\mathrm{H}$. Impact of the Internet on Learning and Teaching. USDLA J 2002; 16(3). Available at https:// www.learntechlib.org/p/93561/

4. Carter TL. Millennial expectations, constructivist theory, and changes in a teacher preparation course. SRATE J. 2009; 18(1): 25-31. 
5. Zahra-Malik M. 2020. The coronavirus effect on Pakistan's digital divide. BBC-Worklife. Available at https://www.bbc.com/worklife/article/20200713-thecoronavirus-effect-on-pakistans-digital-divide

6. Sabah NM. Students' attitude and motivation towards elearning. In proceedings of the first international conference on applied sciences Gaza-Palestine. The First International Conference on Applied Sciences 2013; pp 1-6.

7. Sun A, Chen X. Online education and its effective practice: A research review. J Inform Technol Educ. 2016; 15(1): 157-90.

8. Soni VD. Global impact of E-learning during COVID-19. SSRN Electronic J 2020. [Accesssed on 13 Nov 2020].

9. Wiramihardja E, Kuasa W, Lio A, Badara A. Towards 'the Best of Both Worlds': what learning activities are conducted where? Rec Res Eng Educ. 2018; p.179-86.

Dr Khadija Qamar

Professor of Anatomy

Army Medical College/

National University of Medical Sciences (NUMS)

Rawalpindi Pakistan

Dr Faiza Kiran

Assistant Professor Health Professions Education Army Medical College/

National University of Medical Sciences (NUMS)

Rawalpindi Pakistan 